\title{
ADAPTASI TEKS SEJARAH KEPADA FILEM: KAJIAN BANDINGAN TEKS \\ SEJARAH KERAJAAN MELAYU PATANI KEPADA FILEM QUEENS OF LANGKASUKA
}

\section{(Adaption of History Text to Film: Comparative Study of Text Sejarah Kerajaan Melayu Patani into Film Queens of Langkasuka)}

\author{
Mohamed Nazreen Shahul Hamid* \\ mohamednazreen25@gmail.com
}

Md. Salleh Yaapar

mdsalleh@usm.my

Pusat Pengajian Ilmu Kemanusiaan, Universiti Sains Malaysia.

Sahidin Nitiphak

Faculty of Liberal Arts,

Princess of Naradhiwas University.

Terbit dalam talian (published online): 7 Julai 2020

Sila rujuk: Mohamed Nazreen Shahul Hamid, Md. Salleh Yaapar, dan Sahidin Nitiphak. (2020). Adaptasi Teks Sejarah kepada Filem: Kajian Bandingan Teks Sejarah Kerajaan Melayu Patani kepada Filem Queens of Langkasuka. Melayu: Jurnal Antarabangsa Dunia Melayu, 13(2), 299-318.

\begin{abstract}
Abstrak
Filem Queens of Langkasuka merupakan filem adaptasi daripada teks Sejarah Kerajaan Melayu Patani. Kehebatan raja-raja perempuan Patani telah menarik perhatian banyak pihak hingga detik-detik sejarah pemerintahan mereka difilemkan. Persoalannya, adakah fakta dan peristiwa dalam filem sama seperti yang terdapat dalam sumber asalnya ataupun fakta dan peristiwa tersebut telah ditambah, dibuang dan dikekalkan. Oleh itu, objektif utama kajian ini adalah untuk membandingkan
\end{abstract}

(C) Dewan Bahasa dan Pustaka. 2020. This work is licensed under the term of the Creative Commons Attribution (CC BY) (http://creative commons.org/licenses/by/4.0/)

ISSN 1675-6460 e-ISSN 2682-8049 
filem Queens of Langkasuka dengan teks Sejarah Kerajaan Melayu Patani untuk memperlihatkan sejauh mana wujudnya persamaan antara filem dengan teks sejarah. Objektif kedua, iaitu melihat teknik adaptasi yang digunakan oleh pengarah. Bagi mencapai objektif ini, teori adaptasi telah digunakan untuk melihat aspek yang ditambah, dibuang dan dikekalkan. Bertepatan dengan itu, kajian ini menggunakan kaedah kualitatif dengan melakukan analisis teks, filem dan perbandingan keduaduanya. Kajian ini mendapati bahawa ketiga-tiga teknik adaptasi ini telah digunakan oleh pengarah dan penulis skrip untuk menghasilkan filem adaptasi Queens of Langkasuka. Dalam konteks perbandingan, banyak yang ditambah, di samping banyak pula yang dibuang dan diganti atau sengaja diubah. Justeru, filem Queens of Langkasuka berjaya berdiri sebagai sebuah karya seni yang tersendiri dan berbeza daripada teks sejarah diadaptasikannya.

Kata kunci: Sejarah Kerajaan Melayu Patani, Queens of Langkasuka, Patani, sejarah, adaptasi

\begin{abstract}
Queens of Langkasuka is a film adaptation of the historical text entitled Sejarah Kerajaan Melayu Patani. The eminence of the female rulers of Patani is noteworthy, and has resulted in this film adaptation. The question is whether the facts and events in the film are as reflected in the original source, or if there have been any additions or omissions, and what of the original has been maintained. Therefore, the main objective of this study is to compare the film Queens of Langkasuka with the text of Sejarah Kerajaan Melayu Patani to view the extent of similarity between the film and the historical text. The second objective is to examine the adaptation techniques used by the director. To this end, adaptation theory was used to identify anything that has been added, removed or retained. This study was conducted using a qualitative method for text and film analysis and comparison, and it finds that all three adaptation techniques were used by the director and scriptwriters in the film Queens of Langkasuka. Comparison reveals that while much was added, much was also discarded and replaced or intentionally modified. Thus, Queens of Langkasuka is a successful work of art that is distinct from the historical text on which it is based.
\end{abstract}

Keywords: Sejarah Kerajaan Melayu Patani, Queens of Langkasuka, Patani, history, adaptation 


\section{PENDAHULUAN}

Sejarah perkembangan filem berlaku dengan begitu pesat, pembikin filem sentiasa berusaha mencari sumber dan idea untuk menghasilkan filem mereka. Genre novel sentiasa mendapat perhatian kerana persamaan dari segi unsur naratif yang ada antara satu sama lain. Namun begitu, karya berlatarbelakangkan sejarah kemudiannya turut menjadi pilihan popular para penghasil filem. Karya ini wujud untuk mewakili cerita yang ada dalam sesuatu peristiwa sejarah. Dalam konteks masyarakat kini, sejarah semakin dipinggirkan kerana dianggap sebagai suatu yang tidak menarik dan membosankan. Walau bagaimanapun, apabila sejarah tersebut berjaya ditransformasikan dalam bentuk media seperti filem, hasilnya menjadi sesuatu yang menarik dan tampak lebih hidup berbanding teks-teks sejarah (Guynn, 2006, p.6). Maka, tidak hairan ramai pembikin filem mula berminat untuk mengadaptasi teks sejarah.

Filem sejarah menjadi medium komunikasi untuk memberikan gambaran terhadap sesebuah budaya masyarakat dan negara. Malah, filem turut membantu masyarakat mengimbas kembali sejarah yang berlaku pada masa lampau menerusi visual dan audio. Hughes (2007, p. 1) pernah menyatakan bahawa pembelajaran menerusi buku catatan kurang menarik jika dibandingkan dengan sejarah yang telah ditransformasikan menjadi filem. Meskipun begitu, filem adaptasi teks sejarah juga tidak dapat lari daripada kontroversi seperti yang terjadi kepada adaptasi karya sastera. Oleh sebab peralihan medium, filem adaptasi tidak boleh dilakukan tanpa sebarang penambahan, pembuangan dan olahan daripada teks asal. Hal ini ditambah lagi dengan unsur dramatik yang dimasukkan apabila sesuatu filem dihasilkan dalam usaha menarik minat khalayak untuk terus menonton. Oleh itu, perbandingan karya asal dengan hasil adaptasinya sentiasa menjadi topik perbincangan.

Di alam Nusantara, salah satu filem sejarah yang menarik untuk dibincangkan ialah filem Queens of Langkasuka atau Puen Yai Jom Salad (2008) yang telah diadaptasi daripada teks Sejarah Kerajaan Melayu Patani (2002) oleh Ibrahim Syukri. Kehebatan Patani, terutamanya semasa pemerintahan Raja-raja Pelangi, telah menarik perhatian Nonzee Nimibutr seorang bangsa Thai untuk menghasilkan filem tersebut. Namun begitu, bagi masyarakat Patani ${ }^{1}$, filem ini seolah-olah telah dihasilkan dengan ideologi pengarah yang begitu tebal lalu telah menutup sejarah sebenar. Oleh itu, makalah ini mengkaji filem Queens of Langkasuka dengan menggunakan teori adaptasi yang diketengahkan beberapa tokoh yang menitikberatkan keutuhan sesuatu karya baharu selain meneliti unsur-unsur persamaan dan perbezaan dengan 
karya asal. Kaedah kajian ini bersifat kualitatif dengan melakukan analisis terhadap teks, filem dan akhir sekali perbandingan terhadap kedua-duanya.

\section{FILEM QUEENS OF LANGKASUKA: SELAYANG PANDANG}

Queens of Langkasuka ialah sebuah filem genre kembara fantasi sejarah (historical fantasy adventure) yang menceritakan dengan penuh aksi kisah yang berlaku dalam kesultanan Melayu Patani dalam filem ini disebut Langkasuka. Perhatian khusus diberikan pada era pemerintah perempuan pertama yang ditabalkan menjadi raja dan dikenali sebagai Ratu Hijau. Di bawah pemerintahan baginda, Langkasuka berjaya muncul sebagai sebuah kerajaan yang terkenal. Namun begitu, pada masa itu berlaku pergolakan dan pertumpahan darah sehingga mengakibatkan keturunan Seri Wangsa tergugat. Aksi dalam filem banyak berkembang di sekitar perebutan kuasa oleh Putera Rawai, ancaman lanun dan usaha mendapatkan meriam yang jatuh ke dasar laut.

Filem Queens of Langkasuka telah diterbitkan oleh syarikat perfileman Sahamongkol Film International dan telah menelan perbelanjaan melebihi RM20 juta. Oleh sebab filem ini berlatarbelakangkan sejarah, maka pembikinannya mengambil masa selama lima tahun untuk disiapkan. Filem ini diarahkan oleh Nonzee Nimibutr dan bersandarkan kepada kekuatan skrip yang ditulis oleh Win Lyovarin. Pengarah dan penulis skrip telah bekerjasama untuk mengadaptasi karya sejarah berdasarkan sejarah Patani yang sebenar. Judul asalnya dalam

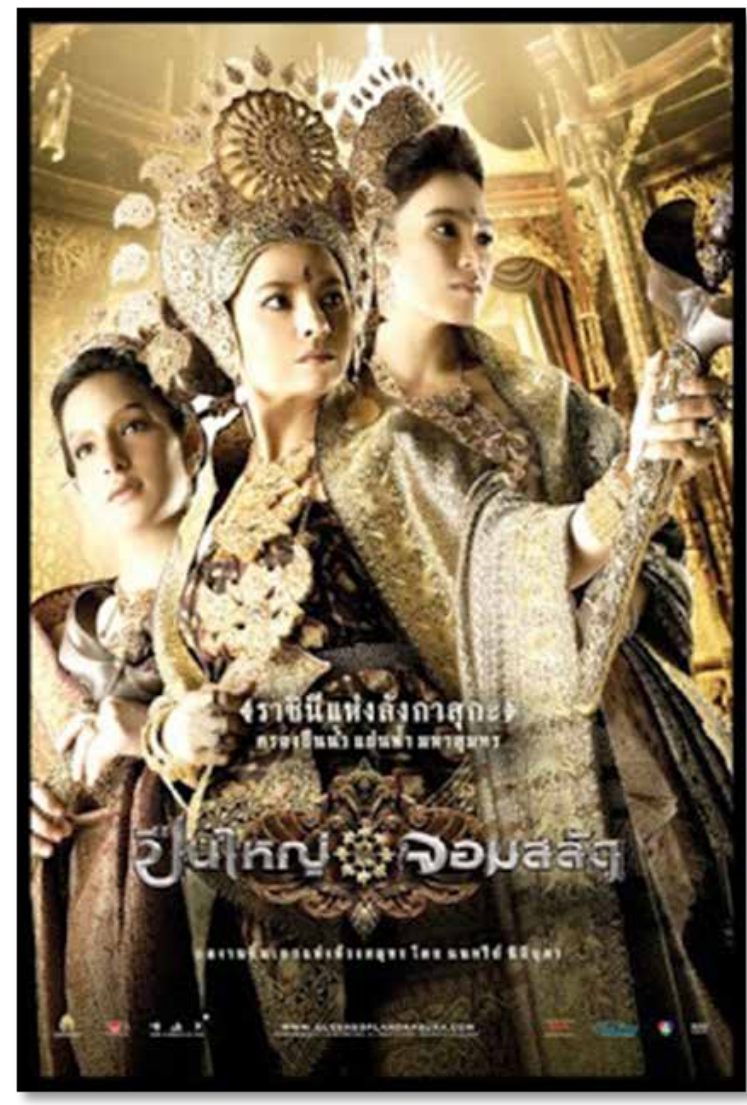

Rajah 1 Poster filem Queens of Langkasuka (Puen Yai Jom Salad).

(Sumber: Asian Wiki.com) 
bahasa Inggeris ialah Queens of Pattani, tetapi ditukar kepada Queens of Langkasuka untuk mengelak kaitannya dengan konflik dan gerakan pemisah di Patani. Filem ini telah ditayangkan di pawagam buat pertama kalinya pada 23 Oktober 2008 dan telah berjaya menarik perhatian ramai penonton di Thailand. Malah, turut berjaya memenangi banyak anugerah bukan sahaja di Thailand tetapi di beberapa negara lain juga.

\section{KERANGKA TEORI ADAPTASI TEKS KEPADA FILEM DAN METODOLOGI KAJIAN}

Kajian ini menggunakan teori adaptasi untuk melakukan analisis. Umumnya, adaptasi bererti pengubahan dan transformasi sesuatu kepada satu situasi yang baharu. Antara teori adaptasi yang tuntas ialah teori yang diperkenalkan oleh Brian McFarlane melalui bukunya, iaitu Novel into Film: An Introduction to the Theory of Adaptation (1996). Menurut McFarlane (1996, p. 10), Geoffrey telah mencadangkan tiga bentuk adaptasi seperti yang berikut:

(1) Transposition, in which a novel is given directly on the screen with a minimun of apparent interfece.

(2) Commentary, where an original is taken and eiher purposely or inadvertently altered in some respect... when there has been a different intention on the part of the film-maker, rather than infidelity or outright violation.

(3) Analogy, which must represent a fairly considerable departure for the sake of making another work of art.

Berdasarkan buku tersebut, transposition bermaksud adaptasi itu boleh dilakukan secara terus oleh penulis skrip dan pengarah filem, iaitu dengan sedikit perubahan. "Commentary" pula bermaksud, pengarah boleh mengubah sedikit dan mentafsirkan sesebuah karya berdasarkan konsep penampilan dalam filem itu. Analogi (analogy), melibatkan perubahan dalam usaha untuk menghasilkan karya berbentuk lain.

Selaras dengan pandangan dalam buku yang sama, Michael Klein dan Gilian Parker (McFarlane, 1996, p. 11) menyatakan tiga kaedah penting dalam proses adaptasi adalah seperti yang berikut: 
... first, 'fidelity to the main thrust of the narrative': second, the approach which 'retains the core of the structure of the narrative while significantly reinterpreting or, in some saces, deconstructing the source test': and, third, regarding 'the source merely as raw material, as simply the occasion for an original work'.

Petikan tersebut menegaskan terdapat tiga jenis adaptasi. Pertama, kesetiaan terhadap karya asal, iaitu pengarah tidak perlu memasukkan idea lain daripada yang sedia ada. Kedua, struktur teks asal dikekalkan dengan tafsiran baharu terhadap bahagian-bahagian tertentu. Ketiga, teks asal hanya dijadikan sumber atau bahan mentah untuk menghasilkan karya yang baharu dan juga berbeza sama sekali.

Secara ringkasnya, adaptasi ialah usaha untuk mentransformasikan karya asal dalam bentuk karya yang berbeza. Tugas ini memerlukan pentafsiran dan kreativiti. Dari segi material bukan semua unsur cerita berubah dan bukan semuanya dikekalkan. Hal ini seperti yang dinyatakan oleh De Witt Bodeen dalam buku yang sama (McFarlane, 1996, p.7), iaitu:

Adapting teks to film is, without a doubt, a creative undertaking, but the task requires a kind of selective interpretation, along with the ability to recreate and sustain an established mood.

Oleh itu, dapat difahami bahawa adaptasi ialah suatu usaha kreatif yang memerlukan tafsiran terpilih bersama-sama keupayaan untuk mencipta dan mengekalkan suasana karya dengan baik dan mantap. Beja (1979, p. 52) dalam buku Film and Literature telah menyatakan hubungan antara filem dengan sastera seperti yang berikut:

Both print and film surround us every day of our lives and can hardly be avoided in modern society; as a result, they are tremendously important forces in our culture.

Selaras dengan pandangan tersebut, Bluestone (1957, p. 2) dalam bukunya Novel into Film ada menyatakan bahawa hubungan antara teks dengan filem sudah bermula sejak awal lagi, banyak filem adaptasi bergantung pada novel:

On the face of it, a close relationship has existed from the beginning. The reciprocity is clear from almost any point of view: the number of films based on novels; the search for filmic equivalents of literature; the effect of adaptations on reading; boxoffice receipts for filmed novels. 
Maka, untuk menjadikan sebuah filem adaptasi tersebut berjaya, pengarang melakukan perubahan, penambahan dan cuba menyesuaikan cerita dalam teks dengan filem yang ingin atau mahu dihasilkan.

Selain itu, menurut Beja (1979, p. 82) lagi, proses adaptasi menggunakan dua proses yang umum, iaitu integriti dan kesesuaian seperti dalam petikan di bawah:

There are probably two basic approaches to the whole question of adaptation. The first approach asks that the integrity of the original work-the novel, say-be preserved, and therefore that it should not be tampered with and should in fact be uppermost in the adapter's mind. The second approach fells it proper and in fact necessary to adapt the original work freely, in order to create-in the different medium that is now being employed-a new, different work of art with its own intregrity.

Dengan kata lain, filem perlu memilih peristiwa dan meringkaskannya, dan dalam waktu yang sama juga harus mengekalkan semangat dan kekuatan karya yang dijadikan sandaran. Malah, karya asal perlu disesuaikan dengan bebas dalam medium baharu.

Seterusnya, harus diketahui bahawa adaptasi bukan hanya terhad dilakukan terhadap teks sastera sahaja. Pada hakikatnya, terdapat pelbagai teks dan bermacammacam bidang boleh dipilih untuk diadaptasi seperti teks sejarah, biografi dan lainlain lagi. Misalnya, siri adaptasi The Crown yang menceritakan kehidupan Queen Elizabeth II berdasarkan fakta sebenar. Melalui siri adaptasi tersebut, masyarakat seluruh dunia mengetahui pelbagai cerita di sebalik istana diraja England yang sebelum ini dirahsiakan. Selain itu, terdapat juga adaptasi komik kepada filem Spiderman: Far From Home (2019), adaptasi daripada teks sejarah lagu Brazil yang popular menjadi filem Veja Esta Cancao (1987), adaptasi daripada teks teater kepada filem The Phantom of Opera (2004) dan sebagainya. Berdasarkan beberapa contoh filem adaptasi tersebut jelas bahawa adaptasi membuka ruang kepada pembikin filem untuk memilih teks yang dirasakan bersesuaian. Adaptasi daripada karya dalam pelbagai bidang merupakan alternatif kepada syarikat penerbitan filem untuk menarik minat penonton. Cita rasa penonton berbeza-beza, dan tidak semua cenderung kepada karya sastera sahaja. Maka, tidak hairanlah teks Sejarah Kerajaan Melayu Patani diadaptasi menjadi filem Queens of Langkasuka.

Berdasarkan teori yang dibincangkan, penulisan makalah ini menggunakan metodologi atau kaedah kajian berbentuk kualitatif. Kaedah kajian yang digunakan ialah analisis teks dan filem secara komprehensif. Seterusnya perbandingan terhadap kedua-duanya dibuat bagi memperlihatkan kaedah adaptasi yang digunakan bagi 
menghasilkan filem Queens of Langkasuka yang berdasarkan teks Sejarah Kerajaan Melayu Patani.

\section{ANALISIS PERBANDINGAN TEKS DENGAN FILEM}

Pada amnya tiga prinsip adaptasi, iaitu penambahan, pembuangan dan pengekalan terhadap teks merupakan prinsip penting yang digunakan oleh pengarah filem dan penulis skrip untuk menghasilkan filem adaptasi Queens of Langkasuka. Berdasarkan ketiga-tiga prinsip yang dikemukakan oleh McFarlane (1996, pp. 10-11) ini, maka perbandingan teks Sejarah Kerajaan Melayu Patani dengan filem adaptasinya yang dilakukan dapat mengenal pasti persamaan dan perbezaan antara kedua-duanya. Selain itu, kekuatan Queens of Langkasuka sebagai karya tersendiri juga dapat ditonjolkan. Maka, analisis perbandingan teks dengan filem dibincangkan seperti yang berikut:

\section{Tokoh dan Peristiwa yang Diubah Suai}

Pari merupakan salah seorang watak yang penting dalam filem ini. Watak atau tokoh seperti ini tidak terdapat dalam teks sejarah. Watak ini direka oleh Win dan Nonzee sebagai faktor penggerak cerita dan watak yang menjamin kesinambungan antara babak-babak yang ada atau ditampilkan (Guynn, 2006, p. 13). Pari watak menarik yang penuh dengan unsur tragis dan magis.

Pari anak yatim piatu selepas keluarganya dibunuh oleh sekumpulan lanun yang diketuai oleh Ekadam dengan menggunakan senjata api dan ilmu sakti. Ia telah diselamatkan oleh bapa saudaranya Anya, dan membesar di Kampung Ledang, sebuah perkampungan laut. Ia mempunyai bakat dan kebolehan untuk mempelajari ilmu sakti Du Lam sejak kecil lagi. Pelbagai cabaran telah ditempuhi oleh Pari sepanjang kehidupannya, termasuklah kehilangan keluarganya, isterinya Bintang yang mati dibunuh, dan kampung kediamannya yang dimusnahkan oleh koncokonco lanun. Peristiwa tragis yang dialami oleh Pari ini digunakan oleh penulis skrip dan pengarah dengan baik untuk mengetengahkan beberapa perkara seperti ilmu kesaktian, perbalahan, pembalasan dan perdamaian. Hal ini boleh dilihat dalam keseluruhan jalan cerita apabila pengarah meletakkan watak Pari dalam isu perbalahan dan pembalasan. Pari juga nekad menuntut bela atas kematian setiap orang yang disayanginya. 
Isu menuntut bela dan percubaan membalas dendam ini boleh dihubungkaitkan dengan peristiwa yang terdapat dalam teks Sejarah Kerajaan Melayu Patani, iaitu ketika Sultan Muzaffar Syah (Raja Patani ketika itu) ingin menjalinkan hubungan persahabatan dengan negeri Siam-Thai. Dalam peristiwa ini, lawatan raja Melayu itu tidak dialu-alukan oleh Raja Siam-Thai. Sambutan dingin tersebut menyebabkan baginda berasa marah dan ingin membalas dendam terhadap Raja Siam-Thai. Raja Patani mengambil keputusan untuk menyerang Ayuthia (Ibrahim, 2002, pp. 3738). Dalam teks sejarah juga, khususnya ketika pemerintahan raja-raja perempuan, serangan atau peperangan hanya akan berlaku jika sesebuah kerajaan ingin menakluk negeri lain dan ingin memperluas kekuasaan mereka. Hal ini boleh dilihat semasa pemerintahan Raja Hijau, iaitu ketika negeri Patani maju dari segi ekonomi dan memiliki pelabuhan yang besar dan menjadi tumpuan para pedagang dan santri. Melihat kemajuan tersebut, Raja Siam-Thai, iaitu Phra Narasuen menggunakan alasan untuk melancarkan perang terhadap Patani bagi meluaskan jajahan takluk mereka (Ibrahim, 2002, p. 44).

Selain Pari terdapat watak Yarang dalam filem ini. Yarang ialah pengawal peribadi Raja Langkasuka yang gagah dan taat setia. Kesetiaannya kepada raja boleh dilihat menerusi satu peristiwa yang nyaris-nyaris membunuh Raja Hijau. Dalam peristiwa itu Raja Hijau telah cuba dibunuh dengan senjata yang mempunyai jarum yang telah dicelup dengan racun. Dalam usaha menyelamatkan rajanya Yarang tercedera di muka. Menerusi peristiwa ini, pengarah telah menggunakan watak ini sebagai simbol kesetiaan seorang hamba kepada raja yang sanggup menggadaikan nyawa. Dalam teks Sejarah Kerajaan Melayu Patani tidak ada seorang pun pengawal peribadi raja tertentu yang ditonjolkan sedemikian. Yang dicatatkan hanyalah perihal menteri, pembesar, panglima dan hulubalang di raja secara umum. Oleh itu, watak Yarang di sini merupakan hasil imaginasi dan fantasi penulis skrip dan pengarah filem semata-mata, dan sebagai contoh keberanian dan kesetiaan seorang hamba kepada seorang raja. Hal ini sesuai dengan amalan adaptasi dalam seni perfileman. Menurut pandangan Davis (2001, p. 17) kebanyakan filem sejarah dibina di sekitar kisah-kisah tertentu yang menarik perhatian pembikin filem:

Most historical films are organized around a particular story, even when a grand theme has captured the filmmaker's imagination.

Watak seterusnya ialah Krabenkaow-Krabendam. Ia merupakan seorang pertapa yang telah bertapa di sebuah pulau yang jauh terasing daripada alam dan kehidupan 
duniawi. Watak ini juga merupakan imaginasi pengarah filem semata-mata, dan tidak terdapat dalam teks sejarah yang asal. Dalam filem ini, Krabenkaow-Krabendam digambarkan sebagai seorang tuan guru yang hebat dan mempunyai ilmu sakti Du Lam. Krabenkaow-Krabendam pernah bekerja sebagai seorang guru yang mengajar ilmu peperangan kepada tentera istana kerajaan Langkasuka. Selain itu, KrabenkaowKrabendam juga menjadi guru kepada Pari dan Ekadam yang turut mengajar ilmu sakti Du Lam.

Watak ini sengaja dicipta oleh pengarah untuk memberikan gambaran tentang seorang guru yang mahir dalam peperangan dan mengajar ilmu peperangan kepada tentera istana Langkasuka. Dalam teks Sejarah Kerajaan Melayu Patani terdapat seorang Syeikh yang alim bernama Syeikh Safiyy al-Dinn yang datang dari Pasai. Syeikh ini telah dijemput oleh Raja Patani untuk mengajarkan hukum-hakam agama Islam di dalam istana (Ibrahim, 2002, p. 33). Tokoh dan peristiwa dalam sejarah Patani ini telah menjadi ilham untuk pengarah filem mewujudkan watak Krabenkaow-Krabendam yang dijemput oleh Raja Langkasuka untuk mengajar seni ketenteraan kepada tentera kerajaan baginda. Bezanya watak KrabenkaowKrabendam bersifat duaan. Pengarah filem dan penulis skrip telah menjadikan watak Krabenkaow-Krabendam sebagai lambang kepada kedua-duanya kebaikan dan keburukan yang ada pada manusia. Krabenkaow-Krabendam memiliki ilmu sakti Du Lam yang boleh membawa mudarat jika ilmu tersebut tidak mampu dikendalikan oleh pemiliknya. Kesan daripada itu, pemiliknya akan berbelah bahagi sama ada melakukan kebaikan ataupun keburukan. Sifat buruk akan terserlah jika ilmu tersebut tidak digunakan di tempat yang sewajarnya. Krabenkaow-Krabendam sentiasa mengajar anak muridnya untuk melakukan kebaikan dan menghindari kejahatan. Walau bagaimanapun, Krabenkaow-Krabendam akhirnya terperangkap dengan ilmu sakti tersebut apabila dihasut melakukan kejahatan. Krabenkaow yang dahulunya baik telah bertukar menjadi Krabendam yang jahat kerana perasaan ingin membalas dendam atas kematian anaknya telah menguasai dirinya.

Selain yang dinyatakan di atas, ubah suaian juga dilakukan oleh pengarah di sekitar peristiwa semasa berlakunya pertumpahan darah di Langkasuka. Dalam peristiwa ini Krabenkaow-Krabendam (yang asalnya dijemput untuk mengajar ilmu ketenteraan kepada tentera diraja) telah melakukan perbuatan yang tidak senonoh apabila menjalinkan hubungan sulit dengan gundik raja. Ia juga berniat jahat untuk menggulingkan raja Langkasuka yang bernama Sultan Bahadur Syah. KrabenkaowKrabendam berniat untuk membunuh sultan tersebut agar anaknya Putera Rawai dapat ditabalkan menjadi raja Langkasuka. Menerusi peristiwa ini, pengarah telah 
menggunakan watak Krabenkaow-Krabendam bagi mewakili seorang tokoh dalam sejarah yang bernama Raja Bima. Dalam teks Sejarah Kerajaan Melayu Patani, perselisihan faham telah berlaku antara Sultan Bahadur Syah (putera Sultan Mansur Syah) dengan Raja Bima, iaitu anak daripada seorang gundik. Suatu hari ketika Sultan Bahadur Syah bersemayam di dalam istana, Raja Bima datang dan cuba menikam sultan dengan kerisnya (Ibrahim, 2002, p. 40). Dalam filem Queens of Langkasuka pengarah turut menggambarkan watak Krabenkaow-Krabendam yang cuba membunuh Sultan Bahadur Syah, dan keris yang digunakan merupakan keris kepunyaan Raja Bima. Berdasarkan pelbagai peristiwa yang berlaku dalam istana, pengarah cuba menerangkan bahawa mungkin terdapat orang-orang yang bersubahat untuk membuatkan istana kecoh dan menyebabkan keluarga raja saling berbunuhan antara satu sama lain.

Seterusnya, Nonzee Nimibutr juga telah mengetengahkan watak Yanis Bree, iaitu seorang pakar dalam pembuatan meriam yang berasal dari Belanda. Yanis Bree datang melawat Langkasuka. Dalam lawatan tersebut ia telah membawa selaras meriam yang hebat sebagai hadiah kepada Raja Langkasuka untuk mempertahankan negeri baginda daripada sebarang ancaman. Cerita mengenai senjata meriam ini telah mendominasi keseluruhan jalan cerita filem ini kerana meriam merupakan senjata yang penting untuk menghapuskan dan mempertahankan negara daripada serangan musuh. Oleh sebab Yanis Bree berasal dari Belanda, maka adalah penting untuk melihat perkaitan watak ini dengan peristiwa yang terakam dalam teks sejarah. Dalam teks sejarah, memang terdapat utusan negara Belanda yang datang ke Patani untuk urusan perniagaan. Pada suatu ketika sebuah kapal Belanda yang diketuai oleh kapten Daniel Van Der Leck telah berlabuh di pelabuhan Patani dan mempersembahkan barang-barang hadiah kepada Raja Patani (Ibrahim, 2002, p. 43). Kedatangan mereka adalah untuk meluaskan lagi perdagangan mereka di Tanah Melayu, termasuk Patani. Pada awal abad ke-16 Belanda memang telah membina rangkaian perniagaan yang begitu luas di Asia Tenggara yang telah berkembang maju.

Selain yang di atas, Putera Rawai juga merupakan watak yang telah diimaginasikan oleh penulis skrip dan pengarah. Ia merupakan watak antagonis dalaman yang berusaha sedaya upaya untuk merampas takhta negeri Langkasuka. Putera Rawai ialah anak kesayangan Krabenkaow-Krabendam dan merupakan ketua pemberontak. Ia telah menjerumuskan ayahnya Krabenkaow-Krabendam terus menjadi jahat selepas kematiannya kerana ingin menuntut bela.

Dalam teks Sejarah Kerajaan Melayu Patani, tidak wujud tokoh penjarah yang bernama Putera Rawai. Namun, terdapat Nai Chan Tung yang dicatatkan sebagai 
seorang pembelot di negeri Patani. Nai Chan Tung berasal dari Ligor dan tinggal di negeri Patani bersama-sama dengan beberapa orang rakannya. Nai Chan Tung telah berkhidmat kepada kerajaan Patani dan kemudian dilantik menjadi seorang pembesar raja. Namun begitu, ia melakukan pembelotan dengan membocorkan rahsia pertahanan negara Patani kepada pihak tentera Siam-Thai, khususnya Panglima Phraya Kalahum. Selepas perbuatannya terbongkar, Nai Chan Tung melarikan diri ke Singgora (Ibrahim, 2002, pp. 70-71).

Dalam filem terdapat kisah yang hampir sama, tetapi dengan perubahan watak dan butiran peristiwa. Pada babak terakhir filem, Langkasuka telah bersiap sedia dengan alat senjata untuk menentang Putera Rawai dan Ekadam yang cuba merampas takhta daripada Raja Hijau. Ketika senjata meriam dihalakan kepada pihak musuh, Haji Kadir pengkhianat dalam istana telah membunuh tentera di raja dan menangkap Raja Hijau. Ia memaksa Raja Hijau segera menghentikan serangan tersebut. Pengarah filem telah mengetengahkan watak Haji Kadir sebagai pembelot kerajaan Langkasuka. Haji Kadir dikatakan sudah lama bekerja sebagai pembesar Langkasuka dan merupakan musuh dalam selimut yang mahu menghancurkan kerajaan tersebut. Haji Kadir merupakan bapa saudara kepada Putera Rawai dan juga pengintip dari dalam kerajaan Langkasuka. Haji Kadir berhubung dengan anak saudaranya menggunakan burung gagak hitam untuk memberikan maklumat yang diperlukan. Walau bagaimanapun, berbeza dengan Nai Chan Tung dalam sejarah Patani, pembelot ini akhirnya terbunuh. Mesej yang ingin disampaikan oleh pengarah filem ini ialah perbuatan khianat dan belot tidak boleh dipandang ringan, dan hukuman yang setimpal dengannya ialah bunuh.

Selain itu, terdapat perbezaan peristiwa antara filem dan teks sejarah, terutama berkaitan dengan ancaman dan serangan musuh. Dalam teks sejarah, Raja Siam-Thai terkenal sebagai musuh yang ingin menakluk negeri Patani agar menjadi kawasan jajahannya (Ibrahim, 2002, p. 44). Hal ini mengakibatkan peristiwa-peristiwa serangan balas terhadap angkatan Siam-Thai, bermula sejak zaman pemerintahan Sultan Muzaffar Syah hingga ke era Raja Hijau, Raja Ungu, Raja Kuning, Sultan Muhammad, Tengku Lamidin dan Datuk Pangkalan. Untuk menjayakan agendanya angkatan Siam-Thai pula telah berkomplot dengan kompeni Belanda yang berpusat di Betawi bagi mendapatkan bantuan dalam melancarkan serangan (Ibrahim, 2002, p. 56).

Berbeza dengan catatan sejarah, dalam filem Queens of Langkasuka musuh utama ialah pengkhianat dalam istana dan kumpulan lanun. Langkasuka di bawah pemerintahan Raja Hijau digambarkan sering mengalami konflik, serangan dan 
pertempuran dalaman. Serangan dimulakan oleh Putera Rawai yang berkomplot dengan pihak lanun yang diketuai oleh Ekadam untuk merampas takhta Kerajaan Langkasuka. Kelibat Raja Siam-Thai atau angkatan tenteranya sama sekali tidak kelihatan dalam filem ini. Hal ini dapat dimengerti kerana penulis skrip, pengarah dan penerbit filem ini ialah orang-orang Siam-Thai. Malah, inilah juga faktor utama mengapa filem ini diberi judul Queens of Langkasuka, walhal raja-raja perempuan yang kehebatannya dikisahkan ialah raja-raja Patani. Penulis skrip, pengarah dan penerbit jelas tidak mahu membangkitkan semangat rakyat Patani yang sejak dahulu hingga kini terus bergelut dengan kekejaman pihak penjajah Siam-Thai.

Seterusnya, peristiwa yang sangat ketara telah ditambah oleh pengarah ialah berkaitan dengan kisah selaras meriam yang hebat yang telah terjatuh di tengah lautan. Meriam ini terjatuh selepas berlakunya serangan hendap oleh pemberontak yang ingin memilikinya. Dalam teks sejarah, tentera Siam-Thai telah merampas segala harta benda dan pelbagai alat senjata. Senjata yang dirampas termasuklah harta pusaka yang berharga milik orang Patani, iaitu meriam-meriam besar yang menjadi simbol kemegahan Patani. Selaras meriam telah dibawa bersama-sama dengan orang-orang tawanan Melayu Patani ke Bangkok, sementara selaras lagi meriam telah terjatuh ke dalam laut sewaktu tentera Siam-Thai hendak memindahnya naik ke atas kapal (Ibrahim, 2002, pp. 74-75). Dalam filem, penulis skrip dan pengarah telah mengubah jalan cerita mengenai meriam yang terjatuh ke dalam laut itu. Menurut versi mereka, meriam yang tenggelam di dasar laut tersebut telah kembali semula dan berjaya dinaikkan ke darat meskipun hanya seketika. Dalam babak yang terakhir, pengarah telah berjaya memperlihatkan bagaimana meriam ini berjaya dinaikkan, namun akhirnya meriam tersebut telah tenggelam semula di tengah lautan.

Sebenarnya, pengubahan terhadap karya atau teks asal apabila melakukan adaptasi adalah tidak dapat dielakkan. Hal ini selari dengan maksud adaptasi itu sendiri, iaitu mengubah sesetengah isi daripada satu media kepada satu media yang lain. A. Wahab Hamzah (2006, p. 12) telah mengulas dengan lebih lanjut tentang proses adaptasi. Proses ini terkandung konsep konvensi memilih dan memfokuskan, konsepsi dan pemikiran semula dan sekali gus disertai pemahaman terhadap watak yang berbeza antara media dahulu (karya asal) dengan media baharu (karya adaptasi). Field (1990, p. 148) berpendapat bahawa adaptasi sebagai proses menyesuaikan dengan menukar atau menyelaraskan serta mengubah sesuatu untuk mencipta perubahan dalam struktur, fungsi dan bentuk untuk menghasilkan satu pelarasan yang lebih baik. Dalam erti kata lain, karya sastera tetap wujud sebagai karya sastera, sementara itu teks sejarah tetap wujud sebagai teks sejarah, walaupun diadaptasikan kepada filem. 
Menurut Alan Rosenthal dalam bukunya Writing Docudrama: Dramatizing Reality for Film and TV (1995) menyatakan kerja-kerja adaptasi bermakna mengubah, memperbetul, membentuk, memotong dan mempermudah (Hizairi, 1997, p. 68). Malah, Rosenthal turut menyatakan bahawa pemotongan dan penciptaan ini ialah seni dan aspek sebenar dalam proses adaptasi. Beliau menyarankan dua pendekatan, iaitu sama ada mengikut karya asal yang baginya tidak begitu baik atau membuat sesuatu yang baharu. Namun begitu, produk baharu yang dihasilkan ini perlu jujur dan mempunyai semangat tersendiri serta emosi karya asal walaupun karya itu sudah tersalur atau tercipta kepada medium dan teknik berbeza.

Oleh itu, tidak hairan banyak pengubahan dilakukan terhadap teks Sejarah Kerajaan Melayu Patani dalam penghasilan filem Queens of Langkasuka. Selain ubah suai ini telah dilakukan dalam usaha mewajarkan jalan cerita, pengubahan ini juga memperlihatkan bahawa pengarah filem dan penulis skrip mempunyai idea atau pemahaman tersendiri terhadap teks asal. Maka, mereka mahu menghasilkan sesuatu yang baharu tetapi masih menghormati atau mengekalkan mood teks asal seperti yang telah dibincangkan di atas.

\section{Tokoh dan Peristiwa yang Dibuang}

Selain wujudnya tokoh dan peristiwa yang diubah suai, filem ini juga telah meniadakan perkara, tokoh dan peristiwa tertentu. Semua ini dilakukan untuk menyesuaikan dengan jalan cerita dan dengan latar penulis, pengarah dan penerbit sebagai orang Siam-Thai. Oleh sebab filem ini merupakan filem dari negeri Thailand yang sedang menjajah orang Melayu Patani, maka unsur penting yang mencirikan identiti orang Melayu Patani telah ditiadakan. Hal ini termasuklah perbualan dalam bahasa Melayu, nama Patani dan bentuk amalan agama Islam. Sesuai dengan plot dan fokus cerita juga, maka yang ditonjolkan hanyalah kekacauan, konflik, pertempuran dan pembunuhan. Sebaliknya, suasana keamanan dan kemakmuran dalam negeri tidak ditampilkan. Begitu juga, beberapa tokoh penting dalam sejarah seperti UpyaDeca dan Yamada tidak ditampilkan. Sementara tokoh seperti Sultan Bahadur Syah dan Raja Bima disentuh sedikit sahaja.

Upya-Deca merupakan tokoh yang penting dalam teks sejarah. Beliau merupakan panglima angkatan laut Siam-Thai dari Ayuthia yang membawa angkatannya ke Patani untuk menakluk kerajaan Patani yang ketika itu diperintah oleh Raja Hijau. Upya-Deca tidak mampu mengalahkan pertahanan orang-orang Melayu Patani meskipun telah berulang kali menyerang negeri itu (Ibrahim, 2002, p. 44). Secara 
tepat Upya-Deca muncul empat kali, iaitu pada peperangan kali pertama ketika pemerintahan Raja Hijau, kali kedua dan ketiga ketika pemerintahan Raja Ungu dan kali keempat ketika pemerintahan Raja Kuning. Dalam filem, tokoh dan peristiwa ini tidak dihadirkan, besar kemungkinan kerana pihak pembikin filem ingin mengelak kisah konflik Siam-Thai dengan Patani. Mereka tidak mahu menonjolkan kelemahan angkatan Siam-Thai seperti yang tercatat dalam buku Sejarah Kerajaan Melayu Patani.

Yamada berasal dari negeri Jepun dan merupakan orang kepercayaan Raja SiamThai. Yamada telah datang ke negeri Siam-Thai sebagai seorang pegawai tentera yang berkhidmat kepada Raja Siam-Thai dan mengetuai pasukan tentera budiman Jepun di Kota Ayuthia. Sifat kepimpinan yang ditunjukkan oleh Yamada telah menyebabkan Raja Siam-Thai melantiknya sebagai Pesuruhjaya Siam-Thai di Ligor dengan gelaran Upya Sina Phimuk (Ibrahim, 2002, p. 60). Walaupun Yamada tokoh penting dalam sejarah, ia juga tidak dihadirkan dalam filem.

Satu lagi perkara yang digugurkan oleh Nonzee Nimibutr dalam filem Queens of Langkasuka adalah tentang latar belakang Raja-raja Pelangi, iaitu Raja Hijau, Raja Biru, Raja Ungu dan Raja Kuning. Pengarah tidak memberikan fokus dan penekanan tentang asal usul mereka, walaupun Raja Hijau merupakan watak utama dalam filem ini. Sebaliknya, pengarah dilihat lebih memfokuskan kepada watak Pari, iaitu watak rekaan dan imaginasi penulis skrip dan pengarah filem semata-mata. Mereka telah memperincikan watak Pari dan latar belakangnya dari kecil hingga dewasa dengan pelbagai dugaan yang dihadapi dalam hidupnya seolah-olah watak Pari ialah watak utama dalam filem ini.

Seterusnya peristiwa mengenai senjata meriam yang disentuh di atas. Dalam filem, selepas Yanis Bree meninggal dunia, Lim Kiam menjadi watak penting sebagai pakar dalam pembuatan meriam. Lim Kiam telah menerima arahan daripada Raja Hijau untuk membuat meriam sebagai senjata pertahanan negeri Langkasuka. Ia telah menghasilkan selaras meriam dengan nama meriam Maha Lalo. Sebenarnya, dalam teks sejarah Patani terdapat tiga laras meriam yang telah dihasilkan, masingmasing dinamakan oleh Raja Hijau sebagai meriam Seri Negara, Seri Patani dan Maha Lela (Ibrahim, 2002, p. 56). Salah satu daripada meriam itu, iaitu Seri Patani, telah dirampas oleh kerajaan Siam-Thai. Kini meriam tersebut terletak di perkarangan Pejabat Kementerian Pertahanan di Bangkok. Perkara ini telah menyebabkan nama Seri Patani dan Seri Negara tidak muncul dalam filem. Yang muncul hanyalah Maha Lalo yang disamarkan daripada Maha Lela. Jelas tindakan ini diambil untuk mengelak daripada menyebut alatan dan nama yang berkaitan secara langsung dengan Patani. 
Dalam filem ini Nonzee Nimibutr juga tidak memasukkan sikap dan keperibadian Raja Hijau yang sangat prihatin terhadap rakyat jelata. Walhal, dalam teks sejarah Raja Hijau digambarkan sebagai seorang raja yang sangat mengambil berat terhadap kebajikan rakyat jelata. Menurut Ibrahim Syukri (2002, p. 42) Raja Hijau pernah merancang untuk menggali Sungai Gerisek menuju ke hulu hingga bertemu dengan sungai besar di Kuala Temangan agar segala jenis bendang padi rakyatnya dapat mengeluarkan hasil yang lumayan. Perkara ini tidak terdapat dalam filem, kerana pengarah lebih memberikan tumpuan kepada lokasi laut dan pulau dengan kisah meriam dan lanun. Pengarah juga lebih memilih isu sengketa berbanding kisah kedamaian. Menurut Ibrahim Syukri (2002, p. 44) negeri Patani sangat damai dan makmur; orang-orang Patani boleh memakan buah-buahan berpuluh-puluh jenis setiap bulan. Seluruh rakyat jelata hidup dengan aman dan damai, tiada dikacau oleh musuh-musuh. Walaupun dalam filem hal ini ada digambarkan sedikit pada bahagian permulaan, namun pengarah lebih cenderung memilih peristiwa dan suasana yang huru-hara atau kacau-bilau.

Berdasarkan perbincangan di atas, jelas bahawa banyak peristiwa dan tokoh yang telah dibuang daripada teks asal Sejarah Kerajaan Melayu Patani oleh penulis skrip dan pengarah filem ini. Namun begitu, peristiwa dan tokoh yang telah dibuang tidak memberikan kesan negatif terhadap jalan cerita dan persoalan yang ingin ditonjolkan oleh pengarah. Pada kebiasaannya sesebuah filem adaptasi tidak dapat mengelak untuk membuang beberapa sudut bahan asalnya (Rentschler, 1986, p. 23). Apatah lagi jika teks tersebut mengambil latar masa yang cukup panjang, sulit, samar atau bergerak masa lampau tiba-tiba melompat balik kejadian pada masa depan. Pengadaptasi akan memilih bahagian tertentu sahaja seperti konflik dalaman, luaran mahupun bahagian yang amat menarik sekali (A. Wahab, 2006, p. 12). Pengadaptasi perlu bijak untuk memilih bahagian yang ingin diketengahkannya. Oleh itu, dalam filem adaptasi Queens of Langkasuka tidak semua yang terkandung teks Sejarah Kerajaan Melayu Patani dapat dimuatkan. Pengarah filem dan penulis skrip telah menggugurkan banyak peristiwa sejarah dan memberikan fokus pada perihal yang menarik sahaja seperti perubahan kuasa dan pencarian meriam. Hal ini dapat difahami kerana filem memerlukan unsur dramatis yang berterusan dalam menarik perhatian penonton. Malah, jika segala peristiwa sejarah dalam teks asal dimuatkan, filem Queens of Langkasuka akan mempunyai tempoh masa yang terlalu panjang. Tidak seperti teks, filem tidak boleh mempunyai durasi masa yang terlalu panjang kerana boleh membuatkan penonton berasa bosan (Taylor, 1994, p. 67). 


\section{Tokoh dan Peristiwa yang Dikekalkan}

Oleh sebab filem ini merupakan filem adaptasi daripada teks sejarah, maka terdapat tokoh dan peristiwa sejarah yang dikekalkan. Dengan memberikan fokus kepada kisah pemerintahan Raja Hijau, tokoh yang dikekalkan berperanan penting untuk menggerakkan cerita. Antara tokoh tersebut termasuklah Raja Hijau, Raja Biru, Raja Ungu, Putera Pahang, Lim Kiam dan Lim Kho Niew.

Nama-nama tokoh ini dengan perwatakan mereka telah dikekalkan oleh penulis skrip dan pengarah seperti yang terdapat dalam teks Sejarah Kerajaan Melayu Patani. Raja Hijau merupakan anak perempuan sulung Sultan Bahadur Syah. Baginda digambarkan sebagai seorang raja perempuan yang mempunyai azam yang kuat dan cekal menghadapi segala cabaran dalam pemerintahannya, terutama ketika berperang dengan pihak musuh. Raja Biru pula merupakan adik kepada Raja Hijau, iaitu anak yang kedua Sultan Bahadur Syah. Raja Biru digambarkan sebagai seorang yang lemah lembut dan selalu bersama-sama dengan kakaknya ketika menjalankan tugas sebagai duta negeri Langkasuka.

Raja Ungu juga telah dikekalkan sama seperti dalam teks sejarah. Baginda merupakan anak bongsu Sultan Bahadur Syah. Raja Ungu telah dipaksa oleh kakaknya Raja Hijau untuk mengetepikan kekasihnya Pari dan berkahwin dengan Putera Pahang atas alasan untuk menyatukan kedua-dua buah negeri sebagai strategi menentang musuh. Raja Ungu bersetuju berkahwin dengan Putera Pahang demi kerajaan Langkasuka. Putera Pahang merupakan duta negeri Pahang yang paling rapat dengan raja-raja perempuan negeri Langkasuka.

Watak Lim Kiam pula digambarkan sebagai seorang yang bijak kerana mampu mencipta senjata api, khususnya meriam. Lim Kiam yang berasal dari negeri China telah belayar ke Langkasuka dengan kapal Belanda yang diketuai oleh Yanis Bree. Mereka belayarke Langkasuka untuk menyerahkan selaras meriam kepada Raja Hijau sebagai hadiah. Lim Kho Niew pula merupakan adik kepada Lim Kiam yang datang ke Langkasuka untuk mencari abangnya. Lim Kho Niew sanggup mengorbankan diri (membunuh diri) agar abangnya tidak perlu lagi mengikut telunjuk musuh yang mahu menghancurkan kerajaan Langkasuka.

Selain tokoh-tokoh dan nama-nama yang dikekalkan, beberapa peristiwa yang berlaku dalam sejarah juga dimanfaatkan oleh penulis skrip dan pengarah untuk menjadikan perjalanan cerita dalam filem lebih menarik. Antara peristiwa penting dalam teks sejarah yang dikekalkan oleh pengarah adalah seperti yang berikut: 
(1) Pertama, peristiwa Raja Hijau yang sanggup berkorban apa-apa sahaja untuk menjaga kedaulatan negeri Langkasuka yang diperintahnya daripada jatuh ke tangan pihak musuh.

(2) Seterusnya, peristiwa Raja Hijau yang mengadakan majlis perkahwinan antara Raja Ungu dengan Putera Pahang sebelum tercetusnya peperangan dengan pihak musuh. Majlis perkahwinan tersebut telah diadakan di kota istana Raja Ungu. Perkahwinan tersebut merupakan perkahwinan paksa untuk mengukuhkan lagi pertahanan negeri Langkasuka daripada ancaman musuh.

(3) Akhir sekali, penulis skrip dan pengarah juga telah mengekalkan rentetan peristiwa selepas kemangkatan Sultan Bahadur Syah seperti yang terdapat dalam catatan sejarah. Oleh sebab Sultan Bahadur Syah tidak mempunyai putera, maka tiga orang puterinya layak menjadi calon bagi menggantikan tempatnya. Maka para pembesar istana pun bersidang. Mereka mengambil keputusan untuk melantik Raja Hijau, iaitu puteri sulung Sultan Bahadur Syah, sebagai pengganti baginda. Maka, Raja Hijau ditabalkan menjadi raja dan baginda merupakan raja perempuan yang pertama memerintah Patani.

\section{KESIMPULAN}

Secara kesimpulannya, pengarah filem dengan kerjasama penulis skrip telah memainkan peranan penting untuk menghasilkan filem adaptasi Queens of Langkasuka daripada teks sejarah, iaitu Sejarah Kerajaan Melayu Patani. Tiga prinsip adaptasi, iaitu penambahan, pembuangan dan pengekalan telah menjadi asas kepada pengarah filem merealisasikan filem yang bersumberkan sejarah kerajaan dan masyarakat Melayu Patani. Terdapat beberapa watak dan peristiwa ditambah oleh pengarah berdasarkan imaginasinya. Pengarah turut telah memasukkan elemen fantasi dalam filem ini untuk menjadikan perjalanan cerita lebih menarik. Selain itu, terdapat tokoh dan peristiwa yang dikekalkan sesuai dengan konsep filem yang merupakan filem adaptasi yang menggunakan teks sejarah.

Seterusnya, terdapat juga tokoh dan peristiwa yang telah dibuang atau digugurkan oleh pengarah untuk mengelakkan kontroversi. Pengarah memfokuskan skop cerita terhadap kisah pemerintahan Ratu Hijau sahaja. Hal ini demikian kerana pengarah menyasarkan jalan cerita dalam filem yang lebih berfokus dan tidak meleretleret hingga menyebabkan penonton berasa bosan dengan plot cerita yang ingin 
diketengahkannya. Oleh itu, pengarah filem ini telah mengambil langkah bijak, sesuai dengan masa tayangan filem yang terhad, iaitu sekitar dua jam. Oleh sebab filem ini merupakan filem adaptasi, maka terdapat persamaan dan perbezaan yang boleh diteliti dalam filem Queens of Langkasuka dengan teks Sejarah Kerajaan Melayu Patani.

Melalui analisis yang dilakukan, didapati bahawa kaedah adaptasi yang digunakan dalam menghasilkan filem Queens of Langkasuka ialah commentary, iaitu pengarah filem dan penulis skrip telah mengubah beberapa hal dalam teks asal dan melakukan tafsiran sendiri. Oleh yang demikian, Queens of Langkasuka berjaya untuk berdiri sebagai sebuah karya filem kembara fantasi sejarah yang tersendiri dan berbeza daripada teks sejarah yang diadaptasinya.

\section{NOTA}

1 Patani yang dimaksudkan dalam kajian ini ialah kawasan yang merangkumi wilayah Pattani, Narathiwat, Yala dan empat daerah paling selatan di wilayah Songkhla yang majoritinya penduduknya berbangsa Melayu-Islam.

\section{RUJUKAN}

A. Wahab Hamzah. (2006). Cabaran dan Kesetiaan dalam Karya Adaptasi. Dewan Sastera, 12, 11-14.

Beja, M. (1979). Film and Literature: An Introduction. New York: Longman Inc.

Bluestonce, G. (1957). Novel into Film. Berkeley: University of California Press.

Davis, Natalie Zemon. (2001). Film as Historical Narrative. National Forum, 81(2), 16-21.

Field, Syd. (1990). Lakon Layar: Asas Penulisan Skrip. Raja Omar Ibrahim (ter.) Kuala Lumpur: Dewan Bahasa dan Pustaka.

Guynn, W. (2006). Writing History in Film. New York: Routledge Taylor \& Francis Group. Hizairi Othman, (1997). The English Patient: Bukti Harmoni Sastera dan Filem. Dewan Sastera, 11, 62-69.

Hughes-Warrington, M. (2007). History Goes to the Movies Studying History on Film. London: Routledge Taylor \& Francis Group.

Ibrahim Syukri. (2002). Sejarah Kerajaan Melayu Patani. Bangi: Penerbit Universiti Kebangsaan Malaysia.

McFarlane, B. (1996). Novel into Film: An Introduction to the Theory of Adaptation. Oxford: Clarendon Press. 
MELAYU: JURNAL ANTARABANGSA DUNIA MELAYU JILID 13 BIL. 2 JULAI 2020

Rentschler, E. (1986). German Film and Literature Adaptations and Transformations. New York: Methuen.

Rosenthal, Alan. (1995). Writing Docudrama: Dramatizing Reality for Film and TV. Boston: Focal Press.

Taylor, M. (1994). The Actor and the Camera. London: A \& C Black.

Win Lyovarin (Penulis Skrip) \& Nonzee Nimitbutr (Pengarah Filem). (2008). Queens of Langkasuka. Bangkok: Sahamongkol Film International.

Tarikh Peroleh (received): 21 Ogos 2019

Tarikh Terima (accepted): 18 Jun 2020 